\title{
Complexity, Maturity and Competency in the Project Risk Management Environment: A Relational Framework involving the Triple Helix Role Players
}

\author{
E Naidoo', ${ }^{1}$ K Govender ${ }^{2}$ \\ ${ }^{1}$ Da Vinci Institute for Technology Management \\ ${ }^{2}$ University of KwaZulu-Natal
}

Article History: Received: 10 November 2020; Revised: 12 January 2021; Accepted: 27 January 2021; Published online: 05 April 2021

\begin{abstract}
The growth in project activity and rise in project failures emphasises the importance of project management as a discipline in which employee perceptions, knowledge, decision-making and communication play a central role. This is even more apparent when projects affect not only one facet of society, but have far reaching consequences for government, industry and training providers. This paper aims to ascertain whether there is a relationship between complexity, maturity and competence with respect to projects. A multi-method research approach was employed, whereby interviews and a web-based survey were used to collect data from Eskom management and project risk management practitioners. The data and information were used to develop a sense-making framework and propose recommendations to enhance project risk management, where-after, the organization (Eskom) developed a competency framework for project managers.
\end{abstract}

Key words: project management; risk; project complexity; risk management

\section{Introduction}

"Energy is the inherent effort of every multiplicity to become unity" (Henry Brookes Adams).

Electricity plays a vital role in any society and it will play a greater role in the future of the world, particularly where business is concerned. Some of the most significant global construction projects and challenges would centre on power generation and transmission for societal and economic well-being.

The growth in project activity and rise in project failures emphasise project management as a key discipline in which employee perceptions, knowledge, decision-making and communication play a central role in the execution of projects (Azzopardi, 2015). Davis (2016) investigated many project failures and found that poor communication leading to uncertainty, has played a significant role in poor risk management, poor project performance, and inadequate budgeting. The failures raised questions about current project risk management practices, people behaviour and technologies, that negatively impact the successful delivery of projects (Azzopardi, 2015).

Other significant factors contributing to the failure of projects are that projects, systems, products and services have rapidly become more complex (Buckle, 2017). Changes in the internal and external organisational environment which are essential adjustments to projects, and the rate that change takes place, also contribute to complexity in the project management space. Canney and Bielefeldt (2015) attribute project failure to the uncertainty and unpredictability of complex systems, low levels of competency and people not taking responsibility for their actions, thereby implying lack of project governance.

Project failures have put increased demands on organisational processes, people and leaders, making it imperative for them to understand what competencies people should have, to meet these demands successfully. Thus, several organisations have focused on the application of maturity models in their attempt to cultivate and evaluate people's competencies in the execution of complex tasks (Buckle, 2017). Conventional project management processes exacerbate the incompetence of managers and their ability to deal with complex projects where uncertainty and risk are deemed to be higher. The indication is that complex systems need 'softer' or more humanely clarified frameworks, to explain the characteristics of a situation and actions that must be taken to solve an issue (Canney and Bielefeldt, 2015).

\section{The Triple Helix Potential}

This research was motivated by experiences of the primary researcher attained whilst working in project risk management at Eskom, which is a South African parastatal that is the dominant electricity generator and supplier in Africa. It was apparent at the organisation that the conventional project management processes were aggravated by low competence among the teams dealing with complex projects, where uncertainty and risk are perceived to be higher. Eskom had failed to meet many of its electricity supply objectives and obligations, due to various reasons including, the untimely exit of managers with relevant technical and professional competency, the loss and slow transfer of skills, and difficulty in filling job vacancies to replenish the skills shortage. 
In addition, massive expansions at Eskom resulted in the organization having to confront the reality of persistent challenges to delivering on their mandate. Fundamental to the challenges were a shortage of skills in project management, constant political interference, and flawed contracting policies with suppliers (Koopman, 2011). Research has shown that the competency and maturity levels at Eskom are still low (Khalema, Van Waveren \& Chan, 2015), including risk management in the project environment. Eskom management's 'onesize-fits-all' approach to competency and skills development fails to recognize that projects have different complexities (Archibald, 2004).

During the late 1960s and early 1990s, Eskom was considered as world class in power station construction and contract management, since the skills and resources were abundantly available in the country. The oversupply of electricity during this period led to under-investment in the energy sector (Flanagan, 2012), and this affected Eskom between the early 1990s to 2005, during which time Eskom lost most of the skills and resources to other sectors, both nationally and internationally. This evidently contributed to tension between two of the pillars of the triple helix model, namely government and industry.

Given the above, there was a severe shortage of people with the required specialist skills, including skills vital for project management, necessary to support Eskom's mega projects. To this end, the Da Vinci Institute for Technology Management (a private higher education institution) partnered with Eskom which resulted in this research being a synergy between academia, government and industry. This was done to probe the skills base issues, and conducting research that could be practically applied by Eskom to service various industries effectively. This initiative is an example of the practical application of the Triple Helix model, given that the research findings are currently being implemented within the Eskom project management environment.

Eskom plays a critical and strategic role in creating the conditions necessary to encourage positive direct foreign investment into the South African economy. Eskom's undertaking of a huge build programme required them to rapidly escalate skills development and this presented the ideal environment within which to conduct research on project risk management.

The triple helix innovation model which allows for interaction among the various bodies, for them to grow and develop sustainable, innovative solutions (Etzkowitz and Leydesdorff, 2000), is in the context of this study depicted in Figure 1.

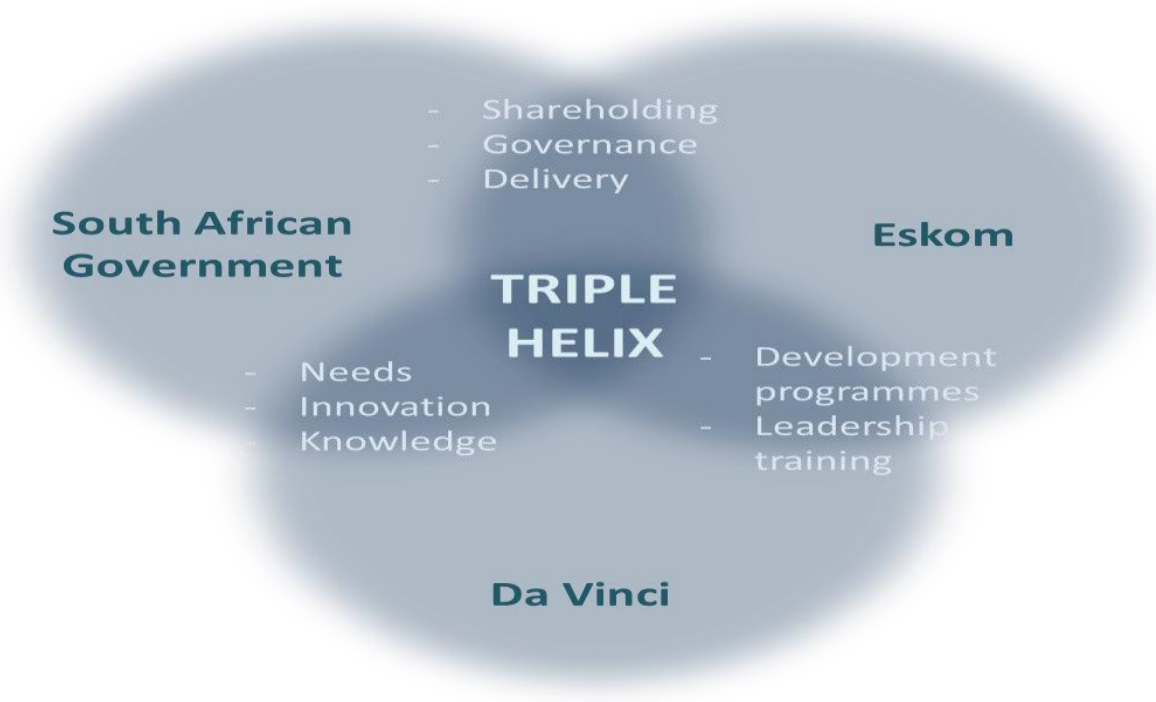

Figure 1. Triple Helix of Tertiary Institutions-Business-Government Interactions Source: Etzkowitz and Leydesdorff, 2000; Naidoo, 2018

\section{Research Problem}

The probability of a relationship between complexity, competency, maturity and project performance became apparent whilst researching the impact of uncertainty and risk within the project context (Naidoo, 2018). However, there seemed to be a gap in the literature with respect to knowledge on the interrelationship between complexity, maturity and competency in project risk management and the influence of such relationships on the performance of projects. Thus, this study was undertaken in an attempt to address the aforementioned by 
formulating the research problem as follows: there is little clarity on the relationship between complexity, maturity and competency in project risk management and whether the relationship affects project performance.

The research was contextualised within a project environment in a major power generating utility in South Africa, because this organisation executed a myriad of projects that were of different complexities, typically contained risks, had high economic and social impact, and were generally time-constrained. Earlier research on maturity and competency indicated that there was a global scarcity of critical competencies that were required for project managers who functioned in the above milieu (Moon, Abd-Karim and Danuri, 2018).

\section{Research Aim and Paradigm}

The aim of the research was to investigate whether a relationship exists between complexity, maturity and competency in project risk management and to determine whether such a relationship affects the performance of projects. The researcher adopted a subjective, multiple-reality ontology through the belief that each individual experiences and interprets the world and data differently (O'Gorman \& MacIntosh, 2015). The ontology was followed by an interpretive research paradigm in which the creation of reality accepts multiple interpretations of the social context (O'Gorman and Mackintosh, 2015). Through analysis and interpretation of the research data, specific actions could be taken, such as discovering patterns in the data, through which meanings and themes emerged. The analysed, coded data presented new theories for a proposal towards a solution for the research problem (Creswell and Poth, 2017). Categories, themes and patterns of meanings that appeared during the research process needed interpretation, understanding and application (Creswell and Poth, 2017), which were addressed through thematic and content analysis. The study followed an interpretive and subjective approach in which data on the phenomenon was deconstructed, interpreted and then reconstructed.

\section{Theoretical Framework}

The theoretical framework was based on the research problem, while broader areas of knowledge and understanding (Swanson, 2013) about complexity, maturity and competency in the project risk management environment were also considered. These insights served as the building blocks to investigate relationships between the research elements within the framework of the Triple Helix concept.

Although there is an abundance of theories on complexity, maturity, and competency, the select studies discussed below, correspond in their collective to transdisciplinary knowledge about organisational systems and project performance. Understanding was created through integration, coverage of the research phenomenon and elements, and the desirability for co-production of knowledge in the project risk management field (Hoffmann, Pohl and Hering, 2017). Relevant theories of the elements and their relationships in the project risk management environment, included systems thinking theory, complexity theory, probability theory, maturity theory and competency theory, were used to retrieve literature in the project management field broadly and specifically on concepts concerning complexity, maturity, competency and the management of risk.

Little (2005) found a relationship between maturity and complexity in projects and Aitken and Crawford (2007), found a relationship between project complexity and competency. The aforementioned opined that organisations need to categorise their projects according to complexity so that the appropriate project competencies can be utilised appropriately. Aitken and Crawford (2007) also reported that higher levels of maturity correlate with higher levels of authority, due to higher competency levels. Therefore, organisational maturity has an impact on the level of authority vested in a project manager. The Helmsman Institute (2012) theorised that by understanding complexity in projects, organisations can improve their investments in developing project management maturity, design applicable systems, and identify those projects that need special focus.

Muller, Geraldi and Turner (2012) confirmed that there is relationship between complexity and competency, which consequently drives project success. Muller, Geraldi and Turner (2012) argued that the 'one-size-fits-all' competency approach is not an effective way to manage projects of varying complexity. All the competency frameworks developed by project management organisations, such as IPMA, GAPPS and APM, use project complexity as a means of differentiating the competencies required by various projects (IPMA, 2006; GAPPS, 2007; APM, 2008). The strong relationship between maturity and competency development (Andersen and Jessen, 2003) was also confirmed by Besner and Hobbs (2008). Some researchers (Backlund, Chroneer and Sundqvist, 2014), assert that the development of competencies is a continuous confidence-building exercise and that learning from experience is part of this development process which resulted in increased maturity. 
It is apparent from the brief literature overview that, in order to achieve high levels of performance, project managers need to have an encompassing and interactive approach to managing complexity, maturity and competency development. The literature review also alluded to a relationship between complexity, maturity and competency and the implications of such a relationship in the project environment.

\section{Research Design and Strategy}

An exploratory and descriptive research approach within an interpretivist paradigm was chosen to gain insight and serve as input to the planning and design of the field research and action plan. The action plan guided the various steps to be taken during the research and served as a link between the research question(s), the field research and the analysis of the collected data (Ormston, et al., 2014). In this study, the behaviours, social attitudes, values and beliefs of participants were explored to determine their impact on complexity, maturity and competency in the organisation and the collective effect of the three elements on project risk management. Through inductive reasoning, the opinions of participants were synthesised and interpreted during data collection, to establish an understanding of commonalities related to the three research elements. The qualitative research approach in the field of project risk management did not only concern data collection and analysis methods, but also a theory-generating activity from which a sense-making framework was developed (Mouton, 2014).

\subsection{Target Population, Sample Size and Sampling Method}

Although the performance of projects affects the entire population of the power generating utility, the responsibility to facilitate the process of project risk management lies with the project risk management practitioners. Thus, the target population for the research comprised all the risk management staff in the project management space, totalling 207. Since the organisational project risk management population was not centralised in one location but spread across various power generating sites, this impacted the inclusiveness of participation and collection of data for a portion of the research.

The research design necessitated the use of different sampling techniques according to which sample sizes were determined for the collection and comparison of the data. A non-probability sampling technique, which included purposive as well as stratified sampling was used. The research process involved identification of experts and the skills and knowledge needed to collect research data to address the research problem (Bless, Higson-Smith and Sithole, 2013).

Purposive sampling was used firstly, by inviting six senior managers for personal, in-depth interviews and secondly, to invite a number of national and international project and risk management experts to verify and critique a checklist containing project risk management competency unit criteria that was generated from the literature review, interviews and web survey. Of the 23 possible respondents, nine experts provided their input in order for the checklist to be finalised (Naidoo, 2018).

For the qualitative web-based survey, stratified sampling as a non-probability sampling technique was applied, to select 207 potential respondents who facilitated risk management in the project environment. The group was selected from four homogeneous segments or strata comprising risk management practitioners, project coordinators and project managers from different organisational divisions. Of the 207 staff members who were invited by email to complete an online questionnaire, only 80 responded. An iterative process for data collection and interpretation was followed, whereby, data was gathered up to a point of saturation when the researcher was convinced that no new input would add to the collective knowledge by inviting additional participants (Bless, et al., 2013).

\section{Research Method and Data Collection}

Essentially, the research design offered a model of what the circumstances in the power generating utility were and what research strategy could be followed to improve the current situation in the organisation (Saunders, Lewis and Thornhill, 2009). Since the research on the topic took place in a sensitive ${ }^{1}$ environment, the discussion of the research was generalised to the development and application of a sense-making framework in a global environment.

\footnotetext{
${ }^{1}$ Eskom is a key strategic state-owned enterprise.
} 
From the literature review, a semi-structured questionnaire with open-ended questions was developed for the interviews, as well as a structured Likert-type questionnaire for conducitng the web-based survey, and a checklist of project risk management competency unit criteria. The findings of the interviews and web survey were triangulated and tested for congruency.

Interviews were conducted with six senior Eskom managers in the project environment. The semi-structured interviews were administered to determine the participants' views on project risk management and the performance of projects in the organisation over the past 10 years. The opinions were recorded and later transcribed, and notes were taken to reinforce reflections on the data during the writing-up of the interview feedback. All six transcripts were combined into a data set to signify the feedback from the repondents and analysed thereafter.

A web-based survey was used as a cost-effective method to obtain data from a larger number of respondents in a consistent through the self-completed questionnaire (Somekh and Lewin, 2011). Data was collected from the population of 207 Eskom-wide project risk managers on categories concerning human experiences and opinions.

A checklist signified the third action-based qualitative data collection and comparison method for the study. The checklist which consisted of project risk management competency unit criteria in tabular format, was sent to a sample of national and international experts in project and risk management. This was done to verify, evaluate and critique the applicability of the different criteria in the project risk management environment. The objective was to ensure consistency of the collected data primarily with the idea to create a project risk management competency framework that followed after the sense-making framework discussed in the original doctoral research (Naidoo, 2018). The unit criteria confirmed by the experts were compared with the data sets from the personal interviews and the web-based survey. Commonalities between the unit criteria in the data sets were examined for inclusion in the project risk management competency framework (Naidoo, 2018).

\section{Data Analysis}

Qualitative data analysis methods included thematic analysis of the interview data set and content analysis for the web-based survey data set. Thematic and content analysis were used to identify fixed themes that emerged from the literature review for comparison with similar themes that emerged from the research data. Both analyses aimed at searching for meaning and patterns in a data set and across data sets. Similar ideas are grouped and coded into categories and themes and evidence gathered from the content. The researcher revisited the data in an iterative process during which potential codes are assigned for the recognition of new patterns and themes (Braun and Clarke, 2006).

\section{Research Findings}

\subsection{Sense-making Framework}

The sense-making framework, which developed from the literature review was confirmed by the findings from the interviews and web survey. Figure 2 provides a depiction of the sense-making framework. Together with the findings from the data sets and the checklist, the the sense-making framework was used to generate a project risk management competency framework ${ }^{2}$ (Naidoo, 2018).

\footnotetext{
${ }^{2}$ The project risk management competency framework is not discussed in this article, since it would increase the length of the paper.
} 


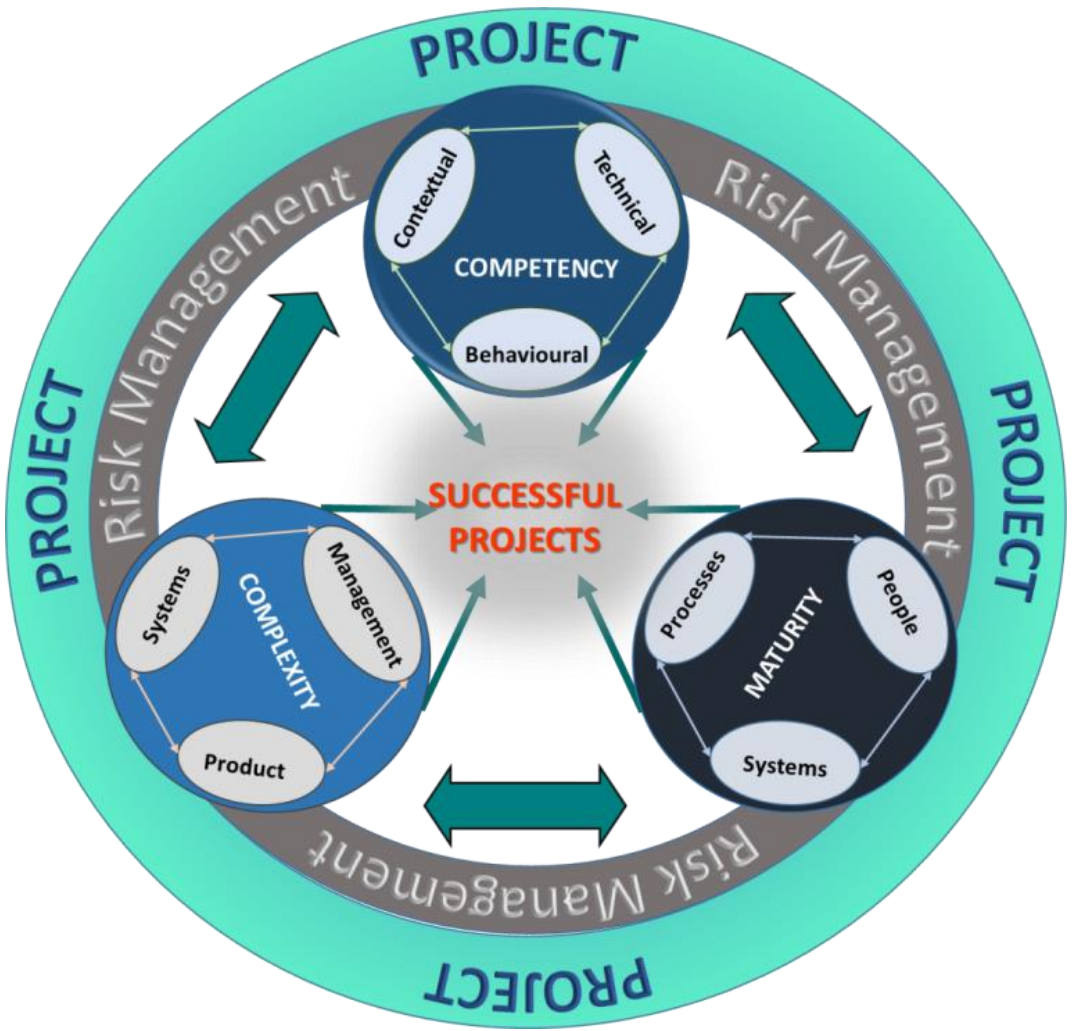

Figure 2. Sense-making framework (Source: Developed by the researcher from the research data)

The sense-making framework was developed to create an understanding of the relationship between complexity, maturity and competency in the project risk management environment, which will contribute to project success. Projects, systems, products and services have rapidly become more complex. People, processes and systems pass through different stages of maturity to remain agile in dynamic business environment. Managing complexity in the workplace therefore requires mature people, processes and systems to ensure success. Competency is closely related to complexity and maturity because it provides guidance and contextual direction in developing the skills, knowledge and attitudes of people in the work place. The process is grounded in experience; transactions between people and the environment; and the creation of new knowledge in business and academia through the support of government as indicated in Figure 3. This once again highlights the crucial relationship fostered by the Triple Helix initiatives.

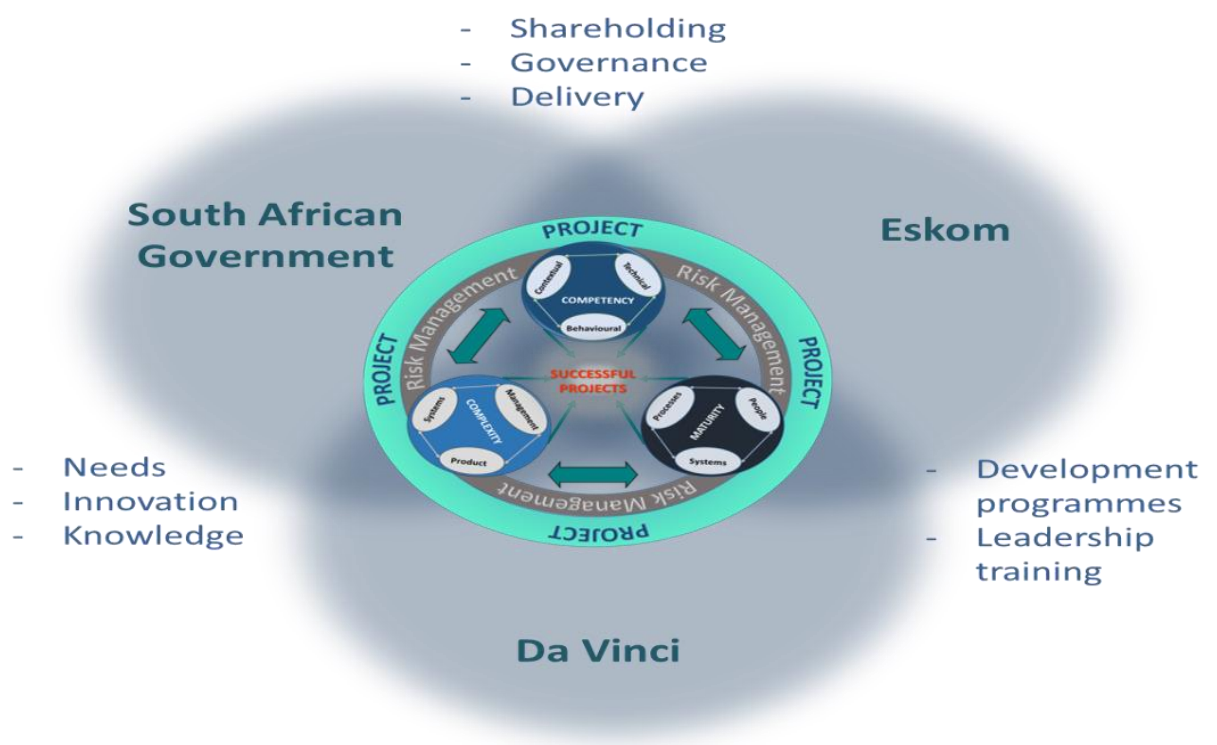

Figure 3. Application of sense-making within Triple Helix Source: Etzkowitz and Leydesdorff, 2000 
A framework for project risk management competency development was created from the sense-making framework and discussd in detail in the thesis (Naidoo, 2018). The thesis includes aspects such as competency elements and their related unit criteria, job roles, proficiency levels, and complexity-based type of projects (Naidoo, 2018). The framework validation required an analytical process to be followed to ensure robustness, rigidity and integrity.

\section{Recommendations}

The recommendations derived from the research are listed for consideration.

- All organisational stakeholders must understand complexity and how the complexity of projects can affect organisational performance.

- $\quad$ Managing complex projects requires a flexible and adaptive approach and not a traditional reductionist style of management. Organisations need to take cognisance of this and develop a management style that is conducive to managing complex projects.

- A risk management culture should be instilled throughout the organisation to ensure maturity in the organisation. The level of maturity of the organisation and its people, processes and systems must be conducive to handle the varied levels of complexity in projects.

- Competency in project management requires knowledgeable, trained people with the right experience.The organisation's people selection and development programmes should take this into consideration.

- The 'one-size-fits-all' competency development approach is not effective and should acknowledge different complexities, especially in the project space.

- Special consideration should be given to understanding, aligning and developing the specific risk management competency outputs required by projects of differing complexities, which in turn enhances the maturity growth process.

- Project performance can be improved by constantly enhancing the competencies of project risk management practitioners.

- $\quad$ The low complex project environment should be used as an incubation area to develop the project risk management practitioners required for high complex environments.

\section{Conclusion}

The findings were compared with the verified checklist of project risk management competency unit criteria so as to create a sense-making framework which was included in a discussion on the Triple Helix model integrating tertiary institutions, business and government.

The scope of the research included the knowledge domains of complexity, maturity, competency and risk management in the project environment. The research focus on project risk management was limited to exploring the relationships between the above research elements and their effect on project performance.

The broader benefits of the research to society is the potential for a more reliable and stable electricity supply that serves business and attracts new business. A stable industrial sector leads to a higher gross domestic product (GDP), higher employment and therefore higher tax revenues, as well as securing a higher rate of investment in the economy by domestic and international investors.

\section{References}

1. Aitken, A., and Crawford, L. H. (2007). A study of project categorisation based on project management complexity. In: Proceedings of IRNOP VIII Conference, University of Sussex. 19-21 September. Brighton, UK: University of Sussex. (Accessed: 14 October 2016).

2. Andersen, E.S., and Jessen, S.A. (2003). Project maturity in organisations. International journal of project management, 21(6), pp.457-461. doi.org/10.1016/S0263-7863(02)00088-1. (Accessed: 02 March 2017).

3. APM. (2008). APM Competence Framework V1. Buckinghamshire, UK: Association for Project Management.

4. Archibald, R. D. (2004). A global system for categorizing projects: the need for, recommended approach to, practical uses of, and description of a current project to develop the system. In: 2 nd Latin American PMIGOVSIG Forum on Project Management in Government, September 21-22. Brasilia, Brazil. (Accessed: 13 December 2017). 
5. Azzopardi, S. (2015). The evolution of project management. Available at: https://www.projectsmart.co.uk/evolution-of-project-management.php. (Accessed: 19 September 2015).

6. Backlund, F., Chroneer, D., and Sundqvist, E. (2014). Project management maturity models-A critical review: A case study within Swedish engineering and construction organizations. Procedia-Social and Behavioral Sciences, 119, pp.837-846. doi.org/10.1016/j.sbspro.2014.03.094. (Accessed: 09 April 2017).

7. Besner, C., and Hobbs, B. (2008). Discriminating contexts and project management best practices on innovative and non-innovative projects: a grounded model and its implications for practice. Project Management Journal, 39(3), pp.S123-S134. doi.org/10.1002\%2Fpmj.20064. (Accessed: 17 May 2016).

8. Bless, C., Higson-Smith, C., and Sithole, A. (2013). Fundamentals of social research methods: An African perspective. $5^{\text {th }}$ Edition. Pretoria, SA: Juta and Company Ltd.

9. Braun, V., and Clarke, V. (2006). Using thematic analysis in psychology. Qualitative research in psychology, 3(2), pp.77-101. doi/abs/10.1191/1478088706qp063oa. (Accessed: 19 September 2017).

10. Buckle, P. (2017). Maturity Models in Systems Research and Practice. In: Proceedings of the 61st Annual Meeting of the ISSS-2017 Vienna, Austria, 2017(1). http://journals.isss.org/index.php/proceedings61st/article/view/3256. (Accessed: 15 November 2017).

11. Canney, N., and Bielefeldt, A. (2015). A framework for the development of social responsibility in engineers. International Journal of Engineering Education, 31(1B), pp.414-424. Available at: https://www.researchgate.net/profile/Angela_Bielefeldt/publication/283226321

_A_Framework_for_the_Development_of_Social_Responsibility_in_Engineers/links/564796bf08 ae451880ac4812.pdf. (Accessed: 12 August 2017).

12. Creswell, J.W., and Poth, C.N. (2017). Qualitative inquiry and research design: Choosing among five approaches. London: Sage publications.

13. Davis, K. (2016). Reconciling views of project success: A multiple stakeholder model. (Doctoral thesis). London: Kingston University. (Accessed: 22 February 2017).

14. Etzkowitz, H., and Leydesdorff, L. (2000). The dynamics of innovation: from National Systems and "Mode 2" to a Triple Helix of university-industry-government relations. Research policy, 29(2), pp.109-123. (Accessed: 19 June 2019).

15. GAPPS. (2007). A Framework for Performance Based Competency Standards for Global Level 1 and 2 Project Managers. Sydney, Global Alliance for Project Performance Standards. (Accessed: 12 July 2017).

16. Helmsman Institute. (2012). Why Project Complexity Matters. Helmsman Institute Pty. http://www.helmsman-international.com/. (Accessed: 10 October 2017).

17. Hoffmann, S., Pohl, C., and Hering, J. (2017). Methods and procedures of transdisciplinary knowledge integration: empirical insights from four thematic synthesis processes. Ecology and Society, 22(1), Article: 27. doi:10.5751/ES-08955-220127. (Accessed: 19 August 2017).

18. IPMA. (2006). ICB - IPMA Competence Baseline, Version 3.0. International Project Management Association. Nijkerk, The Netherlands. www.ipma.ch. (Accessed: 20 November 2016)

19. Koopman, S. (2011). Integrated Demand Management (IDM) Offerings from Eskom. Presentation to South African Institute of Foundrymen. Available at: http://www.slideshare.net/NFTN/eedsminstitute-of-foundrymen?related=1. (Accessed: 25 August 2017)

20. Little, T. (2005). Context-adaptive agility: managing complexity and uncertainty. IEEE Software, 22(3), pp.28-35. doi.org/10.1109/MS.2005.60. (Accessed: 10 October 2017)

21. Moon, A.C., Abd-Karim, S.B., and Danuri, M.S.M. (2018). The Need for a Competencies' Assessment Framework for the Malaysian Construction Project Managers. Journal of Surveying, Construction and Property, 9(1), pp.57-74. doi.org/10.22452/jscp.vol9no1.6. (Accessed: 12 June 2018)

22. Mouton, J. (2014). Understanding social research. Pretoria: Van Schaik Publishers.

23. Muller, R., Geraldi, J., and Turner, J.R. (2007). Linking complexity and leadership competences of project managers. In: Proceedings of IRNOP VIII (International Research Network for Organizing by Projects) Conference. Brighton, UK. (Accessed: 04 August 2017)

24. Muller, R., Geraldi, J., and Turner, J.R. (2012). Relationships between leadership and success in different types of project complexities. IEEE Transactions on Engineering Management, 59(1), pp.77-90. doi.org/10.1109/TEM.2011.2114350. (Accessed: 22 September 2016)

25. Naidoo, E. (2018). Complexity, maturity and competency in the project risk management environment: A relational framework. PhD thesis. Johannesburg: Da Vinci Institute. 
26. O’Gorman, K., and MacIntosh, R. (2015). Mapping research methods. In K. O'Gorman, \& R. MacIntosh (eds.) Research methods for business and management: A guide to writing your dissertation (pp.50-74). Oxford: Goodfellow Publishers.

27. Ormston, R., Spencer, L., Barnard, M., and Snape, D. (2014). The foundations of qualitative research. Qualitative research practice: A guide for social science students and researchers. $2^{\text {nd }}$ Edition. London: SAGE.

28. Saunders, M., Lewis, P., and Thornhill, A. (2009). Research methods for business students, 5th edition. New York: Prentice Hall.

29. Somekh, B., and Lewin, C. eds., (2011). Theory and methods in social research. London: Sage.

30. Swanson, R.A. (2013). Theory building in applied disciplines. San Francisco, CA: Berret-Koeler. 